\title{
EDUCAÇÃO PROFISSIONAL DE NÍVEL TÉCNICO INTEGRADA AO ENSINO MÉDIO: uma análise das escolas profissionalizantes do estado do Ceará
}

\section{PROFESSIONAL EDUCATION LEVEL TECHNICAL INTEGRATED TO HIGH SCHOOL}

\author{
Gilson de Sousa Oliveira ${ }^{1}$ \\ Catarina Angélica Antunes da Silva ${ }^{2}$ \\ Tânia Serra Azul Machado Bezerra ${ }^{3}$
}

\section{Resumo:}

O presente texto, de caráter bibliográfico e documental, traça um panorama geral da educação profissional brasileira e analisa, de modo especial, a perspectiva de educação integral, inaugurada com a promulgação do Decreto $n^{\circ} 5.154 / 04$, que culminou na criação da rede de escolas profissionalizantes do estado do Ceará, a partir de 2008. Trata-se de uma investigação qualitativa, baseadas em documentos oficiais e em estudos que historiciza essa problemática, considerando, sobretudo os aspectos políticos, culturais e socioeconômicos envolvidos no processo, os quais adotam a epistemologia dialética. Identificou-se que, apesar da possibilidade de oferta de uma educação integral, do tipo politécnica e tecnológica inaugurada com este decreto, o ensino desenvolvido nestas unidades escolares tangencia esta perspectiva, priorizando, assim como no passado, as demandas do mercado de trabalho.

PALAVRAS-CHAVES: Ensino Médio - Educação Profissional - Políticas Públicas.

\begin{abstract}
This text, bibliographic and documentary character, traces an overview of the Brazilian professional education and analyzes, in particular, the prospect of comprehensive education, inaugurated with the promulgation of Decree No. 5.154 / 04, which resulted in the creation of the network of schools professionalizing the state of Ceará, from 2008. this is a qualitative research, based on official documents and studies that historicizes this problem, considering especially the political, cultural and socio-economic aspects of the process, which adopt the epistemology dialectic. It was found that, despite the possibility of offering an integral

\footnotetext{
${ }^{1}$ Doutorando em Educação Brasileira. Mestre em Educação Brasileira. Especialização em Gestão Estratégica de IES. Graduado em Pedagogia pela Universidade Federal do Ceará - UFC; Pesquisador ligado ao Laboratório de Estudos do Trabalho e da Educação Profissional -(LABOR). Professor do curso de pós-graduação latu sensu em gestão e coordenação escolar do Conselho Estadual de Educação do Ceará (CEE), promovido pela Coordenadoria Estadual de Formação dos Executivos Escolares para a Educação Básica-CEFEB.

${ }^{2}$ Doutoranda em Educação. Mestra em Avaliação de Políticas Públicas pela Universidade Federal do Ceará UFC. Especialista em Gestão e Politicas Publicas pela Universidade de Juiz de Fora - UFJF. Possui Especialização ainda em Leitura e Produção de textos (2004), pela Faculdade do Vale do Jaguaribe. É graduada em Pedagogia pela Universidade do Estado do Rio Grande do Norte - UERN (2000) e em Letras pela Faculdade do Vale do Jaguaribe (2005). É professora da Graduação da Faculdade Vale do Jaguaribe - FVJ e Professora efetiva do Ensino Médio do Governo do Estado do Ceará.

${ }^{3}$ Professora Adjunta da Universidade Estadual do Ceará. Possui graduação em Pedagogia pela Universidade Federal do Ceará (2004); Mestrado em Educação Brasileira pela Universidade Federal do Ceará (2007) e Doutorado em Educação Brasileira pela Universidade Federal do Ceará (2011). Atualmente é Professora Adjunta da Universidade Estadual do Ceará em Fortaleza. Tem experiência na área de Educação, no setor práticas de ensino. Como pesquisadora atua nas seguintes linhas: Trabalho e Educação; Economia, Política, Sociabilidade e Educação; Também desenvolve pesquisas na área de Educação Infantil e Formação Docente. É Presidente da Associação Internacional de Pesquisa na Graduação em Pedagogia.
}

Revista Labor Fortaleza/CE, jan/jul 2017 Vol.01, nº 17, p. 1-12 ISSN 1983-5000 
education, polytechnic and technological type inaugurated with this decree, the school developed these school units tangency this perspective, priority, as in the past, the demands of the labor market.

KEY - WORDS: Secondary - Vocational Education - Public Policy

\section{INTRODUÇÃO}

Este ensaio teórico de caráter bibliográfico e documental se insere no debate que analisa a reestruturação do Ensino Médio (EM), seus desdobramentos no âmbito da Educação Profissional e discute, a partir de uma perspectiva crítica, a atual proposta de escolarização da classe trabalhadora cearense, promovida por meio das escolas profissionalizantes, as EEEPs. Para embasar esta análise, levou-se em consideração alguns estudos teóricos de autores que se debruçam sobre esta temática no País, a exemplo de Saviani (2007), Frigotto Ciavatta e Ramos (2012), Ramos (2006), Kuenzer (2007, 2009 e 2012) e de alguns documentos oficiais, a saber: a Lei de Diretrizes e Bases da Educação Nacional, $n^{\circ}$ 9.394/96, o Decreto $\mathrm{n}^{\circ}$ 5.154/2004, entre outros. Por último, sugerem-se algumas sugestões para contribuir com o debate, visando, de forma despretenciosa, colaborar na elaboração de possíveis políticas públicas que visem a melhoria da educação daqueles que vivem do trabalho.

\section{Concepções e práticas de Ensino Médio e de Educação Profissional no Brasil: retomando o fio da história}

Ao longo da história brasileira a trajetória da educação profissional tem sido permeada de avanços e retrocessos, todos atrelados ao momento econômico que passa o país, bem como aos interesses políticos existentes em jogo. Como a chegada da família real ao Brasil, se dá a implantação no Recife, a primeira escola de Artes e Ofícios, destinada a capacitar mão-de-obra, afim de dar mais "progresso" ao país e mais conforto e comodidade `a realeza recém-chegada. Em 1930, inicia-se os primeiros moldes de um ensino mais tecnicista. Nos anos de 1950, com o modelo desenvolvimentista de Juscelino Kubistchek, cria-se o "Sistema S" das escolas técnicas pelo empresariado com o apoio do Estado, a fim de qualificar os trabalhadores a fim de atender os objetivos da política nacional implantada, bem como assegurar ao mercado uma produção de qualidade mais competitiva.

A realidade social brasileira inaugurada com o processo de industrialização passou a demandar/exigir um novo papel da escola e dos profissionais que nela trabalhavam. 
Era necessário e urgente formar mão de obra qualificada para atender as necessidades das indústrias que se instalavam no país e ao processo de urbanização decorrente deste fenômeno. Contudo, os problemas trazidos por esta Lei logo demonstraram sua inviabilidade. A escassez de professores e a falta de estabelecimentos de ensino, somados a um enorme contingente de pessoas com baixa ou quase nenhuma instrução escolar eram apenas uns dos vários problemas de difícil solução, naquele período.

Com a promulgação da Lei $n^{\circ} 5.692 / 71$, que reformulou o ensino de $1^{\circ}$ e $2^{\circ}$ graus, a educação profissional passa por uma nova estruturação, incluindo os cursos de capacitação a distância, os chamados cursos por correspondência. Referida legislatura tencionava eliminar o dualismo existente entre escola de $2^{\circ}$ grau normal e escola profissionalizante. Porém, a forma impositiva e compulsória que torna a Educação Profissional etapa final para o Ensino Médio promoveu uma série de problemas para a administração pública e não resolveu o problema da dualidade, pelo contrário, a aprofundou.

A inviabilidade prática dessa Lei serviu de desculpas para que os militares, que estavam a serviço da burguesia nacional, entregassem ao empresariado da educação a tarefa de formar seu quadro de trabalhadores para atender as necessidades da indústria nascente em pleno processo de expansão. Como não havia escolas suficientes, nem professores com formação adequada para tocar esta modalidade de ensino, tal função foi delegada ao Sistema $\mathrm{S}$, mormente às escolas do SENAI, responsáveis pela adoção e aplicação de currículos baseados na ideologia do capital humano (conjuntura da década de 1960 a 1980), bem como nas teses, igualmente ideológicas, da sociedade do conhecimento, da pedagogia das competências (RAMOS, 2006) e da empregabilidade (décadas de 1980 e 1990), todas muito caras ao empresariado nacional.

De acordo com Frigotto (2002), a herança do ciclo de reformas educativas dos governos militares, centrada na ideologia do capital humano ${ }^{4}$, transitou para outro ciclo de reformas, orientadas com base na ditadura do capital, considerada bem mais nociva e contrária aos interesses dos trabalhadores. Na visão deste autor, tais reformas se efetivaram por meio de uma perversa regressão das relações sociais e com o aprofundamento da mercantilização da educação, não só no seu plano institucional, mas, sobretudo, no plano pedagógico.

Na segunda metade dos anos de 1980, com o processo da Constituinte, o País vivenciava um rico processo de disputas no âmbito dos direitos sociais, culminando com uma

\footnotetext{
${ }^{4}$ Para o aprofundamento deste debate, ver (Schultz, 1973, sobre a Teoria do Capital Humano-TCH). 
série de conquistas, incorporadas à Constituição Federal de 1988. Acreditava-se que com a publicação desta Lei, muitos dos novos direitos (educação, saúde, moradia, segurança, trabalho, entre outras), se materializariam por meio de serviços públicos de qualidade, realidade que ainda não se concretizou nem parece fazer parte das agendas de prioridades de nenhum governo brasileiro, até os nossos dias.

No plano internacional, vivia-se uma das mais graves crises econômicas do sistema capitalista de que se tem notícia. De acordo com Mészáros (2000), trata-se de uma crise sem precedentes e completamente diferente das crises vividas por este sistema econômico no passado. De acordo com este pesquisador, pode-se afirmar que a partir deste momento há uma crise estrutural ${ }^{5}$ do sistema capitalista. Neste cenário, todos são fortemente atingidos, porém, seus efeitos são mais devastadores sobre as populações das nações periféricas e dependentes do capital financeiro internacional, a exemplo do Brasil. Defendiase, como saída para aquela crise, uma alargada reforma dos Estados nacionais em todas as áreas, sendo materializada no Brasil por meio de um amplo programa de reformas estruturais, consubstanciadas por meio da privatização de empresas estatais, flexibilização das leis trabalhistas e dos novos contratos de trabalhos, que deu origem, entre outros, ao fenômeno da terceirização, com enormes prejuízos para a classe trabalhadora.

No final da década de 1990, nota-se novamente um impulso em relação a essa modalidade de ensino. Há portanto uma nova onda de "profissionalização" dos trabalhadores, impulsionada pela mudança na economia dos últimos tempos. Essa perspectiva que passa a orientar a escola de ensino médio no Brasil foi particularmente afetada palas novas práticas educacionais advindas da reforma que ocorreu no Brasil no âmbito educacional.

Para Frigotto (2007, p.12), o governo Collor foi quem primeiro iniciou este processo no país, aderindo cegamente à doutrina neoliberal. Porém, foi no governo de Fernando H. Cardoso que é posto em prática o receituário neoliberal de forma competente, em absoluta observância aos aconselhamentos propostos no documento que ficou conhecido como Consenso de Washington ${ }^{6}$, que funcionava como uma espécie de cartilha, elaborada por técnicos das grandes agências de financiamento, notadamente o Banco Mundial e o Fundo Monetário Internacional (FMI), com a qual os governos deveriam ajustar suas plataformas políticas para se adequarem aos objetivos dos centros hegemônicos do sistema capitalista mundial e do seu processo de reestruturação da produção em escala planetária.

\footnotetext{
${ }^{5}$ Para maiores esclarecimentos, convidamos o leitor/a conhecer Antunes (2002).

${ }^{6}$ Realizado em 1989, foi um desdobramento da reunião de integrantes do governo norte-americano e organismos financeiros (FMI e BM).
} 
Em consonância com as reuniões mundiais organizadas pela UNESCO, desencadeou-se um processo de reformas educacionais na América Latina, e particularmente, no Brasil, com o intuito de adequar o País ao processo de reestruturação econômica em curso. Tais reformas foram orientadas a partir de alguns importantes documentos, a saber: Declaração mundial sobre educação para todos, de Jomtien (UNESCO, 1990) e a Declaração de Nova Delhi (UNESCO, 1993). Na perspectiva de tais documentos, os países em desenvolvimento devem realizar suas reformas educacionais, levando-se em consideração o ajuste estrutural, demandado pelo processo de reestruturação produtiva em curso (SILVA JÚNIOR, 2002).

No Brasil, a tradução mais conservadora no âmbito das reformas educacionais ocorreu logo após a promulgação da LDBN, Lei n 9.394/96, em relação ao ensino médio e técnico, mediante o Decreto $\mathrm{n}^{\circ}$ 2.208/97. Referendado por outras medidas legais, como a Portaria Ministerial n ${ }^{\circ}$ 646/97, documento este que aprofundou a histórica dualidade "entre educação geral e específica, humanista e técnica, destroçando, de forma autoritária, o pouco ensino médio integrado existente no país" (FRIGOTTO, 2010, p.32). No entendimento de Kuenzer (2007, p. 15), referido decreto não apenas institucionalizou a dualidade da educação brasileira, marcada de um lado por um tipo de educação de caráter propedêutico, "a ser complementada como formação científico-tecnológica e sócio histórica avançada", aos filhos dos donos dos meios da produção e escola básica como formação final, para os filhos dos trabalhadores.

As expectativas geradas com a eleição de Lula da Silva, em 2003, reacenderam a discussão em torno da necessidade de reeditar o decreto 2.208/97, considerado o ataque mais nocivo aos interesses dos trabalhadores. "Esse processo resultou em uma significativa mobilização dos setores educacionais vinculados ao campo da educação profissional, principalmente no âmbito dos sindicatos e dos pesquisadores da área trabalho educação" (BRASIL, 2007, p. 23), culminando com a promulgação do Decreto $n^{\circ} 5.154 / 2004$, que reestabeleceu a possibilidade de oferta de um ensino médio de caráter politécnico, com currículos que podem integrar-se à formação científica, tecnológica e cultural, cujo escopo é formar indivíduos capazes de articular as dimensões do fazer, do pensar e do sentir.

O termo politecnia, mencionado neste trabalho, tem o mesmo significado de educação tecnológica ${ }^{7}$, ou seja, uma educação capaz de colaborar para que os indivíduos

\footnotetext{
${ }^{7}$ Para Saviani (2003), apoiado em estudos de Manacorda, educação tecnológica é o termo que melhor traduz o significado marxista de politecnia ou de educação politécnica (MANACORDA, Mario, A. Marx e a pedagogia moderna. São Paulo: Cortez/Autores Associados, 1991). Dessa forma, os utilizaremos neste texto como
} 
dominem os fundamentos científicos e tecnológicos das diferentes técnicas que caracterizam os processos de trabalho existentes na sociedade em dado momento histórico. O termo politecnia, portanto, não pode ser compreendido de forma literal, conforme nos esclarece Saviani (2003, p. 140). Para este autor,

Politecnia, literalmente, significaria múltiplas técnicas, multiplicidade de técnicas, e daí o risco de se entender esse conceito como a totalidade das diferentes técnicas, fragmentadas, autonomamente consideradas. A proposta da profissionalização do ensino de segundo grau da Lei n. 5.692/71, de certa forma, tendia a realizar um inventário das diferentes modalidades de trabalho, das diferentes habilitações, como a lei chama, ou das diferentes especialidades. A escola de segundo grau teria a tarefa de formar profissionais nas diferentes especialidades requeridas pelo mercado de trabalho. E é por isso que, no apêndice do parecer 45/72, listavam-se mais de uma centena de habilitações, e ainda ficava em aberto a possibilidade de se incluírem outras que tinham escapado à argúcia ou à capacidade inventariante dos conselheiros.

Sobre as mudanças trazidas pelo Decreto $n^{\circ} 5.154 / 04$, cumpre esclarecer que estas não contemplam a concepção de ensino médio integrado e de educação unitária, politécnica e omnilateral defendidas por professores, estudantes, sindicalistas e outros profissionais ligados à educação. Contudo, como afirmam Frigotto et al. (2005, p.43):

[...] Entendemos que o ensino médio integrado ao ensino técnico, sob uma base unitária de formação geral, é uma condição necessária para se fazer a "travessia" para uma nova realidade. Sabemos que foi essa travessia que o Decreto n. 2.208/97 interrompeu, ao forçar a adequação da realidade à lei, proibindo que o ensino médio propiciasse também a formação técnica. $\mathrm{O}$ restabelecimento dessa garantia por meio do Decreto n. 5.154/2004 pretende reinstaurar um novo ponto de partida para essa travessia, de tal forma que o horizonte do ensino médio seja a consolidação da formação básica unitária e politécnica, centrada no trabalho, na ciência e na cultura, numa relação mediata com a formação profissional específica que se consolida em outros níveis e modalidades de ensino.

De modo geral, a educação destinada à classe trabalhadora, inclusive, aquelas experiências que se autodenominam como educação integrada, de modo geral, não garantem uma formação do tipo omnilateral, de base unitária, perspectiva defendida nessa análise como antítese ao modelo dual em curso. Na prática, as políticas públicas de educação profissional de nível médio têm como horizonte apenas a preparação do jovem trabalhador para o ingresso precoce no mercado de trabalho. A base teórica desses currículos baseia-se, fundamentalmente, pela lógica da Pedagogia das Competências (RAMOS, 2006), do

expressões sinônimas. Entretanto, Saviani (2003) adverte que é preciso ter cuidado com o uso do termo educação tecnológica, em função da apropriação que a concepção burguesa da educação fez do termo tecnologia. 
empreendedorismo e da falácia da empregabilidade, propostas que, além de negarem qualquer perspectiva emancipadora de educação para aqueles que vivem do trabalho, os culpabilizam pelo seu (in)sucesso profissional, uma vez que recai sobre eles a responsabilidade de sua inserção no mundo produtivo, não importando a forma, se por meio do emprego formal ou apenas, como empreendedor individual.

$\mathrm{Na}$ perspectiva de Frigotto, Ciavatta e Ramos (2005b), o Decreto $\mathrm{n}^{\mathrm{o}}$ 5.154/04 representou apenas a forma possível de fazer com que a dualidade no campo da educação básica e da educação profissional fosse pelo menos amenizada no âmbito da legislação. Podese afirmar que tal decreto limita-se apenas a admitir a articulação entre o ensino médio e a educação profissional, numa mesma instituição de ensino, num mesmo curso, com currículo e matrículas únicas e de forma integrada, mas que, ao contrário do que se tem afirmado, a sua estrutura não foi em nada afetada/modificada. Mudar os atuais modelos de escolarização da classe trabalhadora pressupõe, antes de tudo, tomar decisões políticas propositivas, capazes de suplantar o projeto das forças hegemônicas em curso, de modo a reconduzir os sujeitos ao processo criativo e dinâmico do trabalho como autor realização.

As questões que se colocam nesta breve análise são: a formação da classe trabalhadora brasileira atual, realizada nas escolas profissionalizantes do estado do Ceará está comprometida com uma formação que tem como horizonte a emancipação humana?

\section{A proposta de formação das escolas estaduais de educação profissional do Ceará: educação integrada ou em tempo integral?}

O Ensino Médio Integrado à Educação Profissional de Nível Técnico, regulamentado a partir do decreto $\mathrm{n}^{\mathrm{o}} 5.154 / 2004$, bem como a Lei $\mathrm{n}^{\mathrm{o}} 11.741 / 2008$, que alterou o artigo 36 da LDB 9.394/1996, foi apresentado pelo Governo Federal como uma nova modalidade de ensino, adquirindo o mesmo status das outras modalidades de ensino da educação básica. Para viabilizá-lo, o governo Lula editou o Decreto $n^{\circ}$ 6.302/2007, que institui o "Programa Brasil Profissionalizado", objetivando "estimular o ensino médio integrado à educação profissional, enfatizando a educação científica e humanística, por meio da articulação entre formação geral e educação profissional no contexto dos arranjos produtivos" e estabelece, entre outras coisas, que a União se responsabilize não só em fornecer aporte técnico para potencializar a oferta de educação profissional integrada ao 
ensino médio nas redes estaduais de ensino, mas, sobretudo, assegurar seu financiamento (BRASIL, 2007b, p. 1).

O Ceará foi um dos primeiros Estados do Brasil a aderir ao Programa Brasil Profissionalizado. Seguindo os mesmos passos do Governo Federal, foi lançado poucos meses depois um Plano Integrado de Educação Profissional e Integração Tecnológica, por meio da Lei $n^{\circ} 14.273 / 2008$, assegurando a oferta desta modalidade de ensino, por meio da junção de um currículo que une Ensino Médio ao Ensino Tecnológico. Dava-se início no Estado, a implantação de um dos mais ambiciosos programas de expansão da rede estadual de escolas profissionalizantes de nível médio em todos os tempos. Inicialmente, 25 (vinte e cinco) escolas foram adaptadas para oferecer educação profissional de nível médio em jornada de tempo integral. Entre os anos iniciais da implantação da rede até o último ano da gestão do governo Cid Gomes, em 2014, já haviam sido inauguradas 106 escolas em vários municípios.

De acordo com relatório de gestão "O pensar e o fazer da educação profissional no Ceará 2008 - 2014", até o final de 2014, o governo cearense já havia investido mais de R\$ 1.036.000.000,00 (Um bilhão, trinta e seis milhões de reais), fato que evidencia o quanto essa modalidade de ensino passou a ser importante para a gestão do Governo cearense. Cumpre destacar que os investimentos nesse setor foram em parte do Governo do Estado, aproximadamente, $71 \%$ do total e $29 \%$ do Fundo Nacional de Desenvolvimento da Educação do Ministério da Educação (FNDE)/MEC). Acresce-se a este montante, o valor de R\$ 435.904.666,11 (quatrocentos e trinta e cinco milhões, novecentos e quatro mil, seiscentos e sessenta e seis reais e onze centavos) referentes ao custeio relacionado aos anos de 2008 a 2014. (CEARÁ, 2014, p. 103).

O EMI ao regulamentar o $\S 2^{\circ}$ do art. 36 e os arts. 39 a 41 da LDB propõe a superação da histórica dicotomia entre conhecimentos específicos e gerais, entre ensino médio e educação profissional, por meio de um currículo que integra, de forma orgânica, uma sólida formação básica, de caráter propedêutica e uma educação profissional capaz de atender às exigências dos processos produtivos atuais.

A perspectiva da integração do ensino médio à educação profissional $\left(\S 2^{\circ}\right.$ do art. 36 e os arts. 39 a 41 da LDB), para a SEDUC tem como fundamento o pressuposto de que o processo educacional necessariamente "deve ter como referência uma concepção integral do ser humano, que agregue suas diferentes dimensões constituintes com vistas à formação omnilateral dos sujeitos. O trabalho, a ciência e a cultura compõem as dimensões aqui referidas" (CEARÁ, 2014, p.114).Este mesmo documento ressalta que, 
Na formação desse ser integral é imprescindível a compreensão do real como totalidade, o que exige o conhecimento das partes e as relações entre elas. $\mathrm{O}$ movimento da parte para o todo e do todo para a parte possibilita transitar pelos conhecimentos científicos (conhecimentos gerais e conhecimentos técnicos) e dados de realidade (a prática em si), buscando construir novos conhecimentos que deem conta da superação das dificuldades apresentadas na vida cotidiana e no exercício da profissão (IDIM, IBDEM).

Atualmente, existem mais de 50 (cinquenta) cursos ofertados nas escolas profissionalizantes cearenses, em diversas áreas do conhecimento, a saber: Agroindústria; Automação Industrial; Contabilidade; Comércio; Edificações; Eletrotécnica; Eletromecânica; Enfermagem; Mecânica; Mecânica Automotiva; Petróleo e Gás; Informática; Rede de Computadores; Eventos; Guia de Turismo; Hospedagem; Massoterapia; Segurança do Trabalho; Meio Ambiente; Floricultura; Produção de Moda; Tecelagem e outros.

O interesse por estes cursos, de modo geral, é bastante significativo, uma vez que, para a maioria dos jovens matriculados nesse modelo de ensino, a Escola profissional representa uma das poucas oportunidades de superação de um quadro historicamente marcado pela desigualdade de oportunidade entre aqueles jovens que vivem na Capital e na região metropolitana de Fortaleza e aqueles residentes nos demais municípios interioranos. Sabe-se que a maioria dos empregos formais gerados no Estado localizam-se em Fortaleza e nas cidades que compõe a região metropolitana.

O crescente interesse dos jovens pelos cursos técnicos profissionalizantes pode ser contatado pelo número de matrículas nesta modalidade de ensino desde o ano da implantação da rede de escolas no Estado. Em 2008, o governo cearense iniciou as atividades da rede de escolas profissionalizantes, adaptando 25 escolas com pouco mais de 4 (quatro) mil alunos. Este número passa dos 40 mil no final da gestão do governo Cid Gomes, em 2014, representando um aumento nas matrículas de mais de $1.000 \%$. Na visão de Magalhães (2013, p.19),

A rápida expansão das EEEP's, instaladas em municípios de variadas características geográficas, socioeconômicas e culturais, se por um lado representa uma oportunidade para os jovens destes municípios obterem uma formação técnica integrada ao ensino médio, por outro gera expectativas quanto à sustentabilidade do projeto ao longo dos anos.

As principais preocupações da SEDUC consistem em desenvolver políticas de emprego e renda para todos os municípios cearenses, oportunizando assim, o ingresso destes jovens no mercado de trabalho. Porém, esta equação não está resolvida. É grande a discrepância entre o número de empregos criados na região metropolitana de Fortaleza e 
aqueles gerados no interior. A ausência de uma política sistemática de geração de renda e emprego em todo Estado poderá provocar a falência da rede de escolas estaduais de educação profissional por motivos óbvios de não inserção do jovem no mercado de trabalho, seja no município ou na região onde vive. Diante deste agravado cenário, é possível que este projeto propagandeado como uma das maiores oportunidades para os jovens cearenses termine sendo motivo de frustração, comprometendo, inclusive, a sustentabilidade da rede.

A dificuldade de inserir os jovens no mercado de trabalho é apenas um dos muitos problemas vividos pelos gestores destas escolas na atualidade. O estágio, etapa fundamental da formação dos jovens nestes cursos, encontra-se por este motivo, ameaçado, já que o número de empresas que poderia oportunizar uma experiência concreta de trabalho para o educando é insignificante diante da demanda. Além disto, já se vivencia nestas escolas um clima de desconfiança acentuado por parte de alguns gestores, professores e até alunos, quanto ao funcionamento futuro da rede no Estado.

Entretanto, é justo reconhecer que o trabalho realizado nestas escolas tem levado, contrariando as expectativas dos seus idealizadores, - que defendem a EP como etapa final para os jovens trabalhadores, - um número significativo de estudantes a ingressar no Ensino Superior. Na visão de Magalhães (2013), isto ocorre, sobretudo, devido à influência de alguns programas federais, a exemplo do Sistema de Seleção Unificada (SISU), que utiliza os resultados da prova do Exame Nacional do Ensino Médio (ENEM), além do PROUNI e do FIES, ambos responsáveis pela matrícula de milhares de jovens de baixo poder aquisitivo no Ensino Superior.

A intenção do governo cearense em promover a integração do currículo da escola de nível médio, oportunizando EP para uma parcela dos estudantes cearenses, além de não garantir as mesmas oportunidades para todos os estudantes desse nível de ensino, não cria as condições para a superação das clássicas práticas duais da escola brasileira, marcadas por um tipo de ensino destinado aos filhos dos trabalhadores e outro modelo, diametralmente oposto, destinado aos filhos da classe dirigente deste País.

Conclui-se que a perspectiva de educação integrada, sinalizada com o Decreto ${ }^{\circ}$ 5.154/2004, está longe de se concretizar no cenário nacional. Ao contrário da sua inspiração inicial, as experiências de formação da classe trabalhadora, nascidas a partir deste decreto não só negligencia a perspectiva de uma formação omnilateral dos sujeitos, como também perpetua e até aprofunda a dualidade imposta por meio do decreto anterior. 


\section{REFERÊNCIAS}

ANTUNES, Ricardo. Os sentidos do trabalho - ensaio sobre a afirmação e a negação do trabalho. São Paulo: Boitempo, 2002.

BRASIL. Lei $\mathbf{n}^{\circ}$ 9.394, de 20 de dezembro de 1996. Estabelece as diretrizes e bases da educação nacional. Ministério da Educação, 1996.

Decreto 2.208, de 17 de abril de 1997. Regulamenta o $\S 2^{\circ}$ do art. 36 e os arts. 39 a 42 da Lei ${ }^{\circ} 9.394$, de 20 de dezembro de 1996, que estabelece as diretrizes e bases da educação nacional. Brasília, DOU de 18.4.1997.

profissional no Ceará 2008 - 2014

2014. RELATÓRIO DE GESTÃO: O pensar e o fazer da educação

http://www.educacaoprofissional.seduc.ce.gov.br/images/relatorio_de_gestao_2008_2014/rela torio_de_gestao_2008_a_2014.pdf

LEI N ${ }^{\circ}$ 14.273, DE 19 DE DEZEMBRO DE 2008. Dispõe sobre a criação das Escolas Estaduais de Educação Profissional - EEEP, no âmbito da Secretaria da Educação, e dá outras providências. Diário Oficial do Estado do Ceará, Fortaleza, CE, série 2, Ano XI, no 245, 23 dez. 2008.

FRIGOTTO, Gaudêncio. A relação da educação profissional e tecnológica com a universalização da educação básica. In: Educação profissional e tecnológica no Brasil contemporâneo: desafios, tensões e possibilidades. Porto Alegre: Artmed, 2010. FRIGOTTO, G.; CIAVATTA, M.; RAMOS, M. N. (2012). (Orgs.). Ensino médio integrado: concepções e contradições. São Paulo: Cortez.

A política de educação profissional no Governo Lula: um percurso histórico controvertido. In: Educação \& Sociedade, Campinas, v.26, n.92, out. 2005b.

HADDAD, Sérgio (org.). Banco Mundial, OMC e FMI: o impacto nas políticas educacionais. São Paulo: Cortez, 2008.

KUENZER, Acácia Z. Da dualidade assumida à dualidade negada: o discurso da flexibilização justifica a inclusão excludente. Educ. Soc., v. 28, n. 100, p. 1153-1178, out. 2007.

O ensino médio no plano nacional de educação 2001-2010: superando a década perdida? Educ. Soc., v. 31, n. 112, p. 851-873, jul./set. 2010.

São Paulo, Cortez, 2007.

Ensino Médio e Profissional: as políticas do Estado neoliberal. 4 ed.

O Ensino Médio: agora é para a vida: entre o pretendido, o dito e o feito. Revista Educação \& Sociedade, n. ${ }^{\circ}$ 70. Campinas, Abril 2000 b.

Ensino Médio: construindo uma proposta para os que vivem do trabalho. São Paulo: Cortez, 2009. 
MANACORDA, Mario, A. Marx e a pedagogia moderna. São Paulo: Cortez/Autores Associados, 1991.

MARX, K. \& ENGELS, F. Crítica do programa de Gotha. In: MARX, K. \& ENGELS, F. (Orgs.) Obras Escolhidas. São Paulo: Alfa e Ômega, s.d. v.2.

MÉSZÁROS, István. A crise estrutural do capital. In: Outubro-Revista do Instituto de Estudos Socialistas, São Paulo, n. 4. 2000.

NOSELLA, Paolo. Gramsci e os educadores brasileiros: um balanço crítico. In Revista da FAEEBA, Salvador, nº 10, jul./dez. 1998

SAVIANI, Dermeval. O trabalho como o princípio educativo frente às novas tecnologias. In: Novas tecnologias, trabalho e educação: um debate multidisciplinar. $5^{\mathrm{a}}$ Ed. - Petrópolis, RJ: Vozes, 1999.

SECRETARIA DE EDUCAÇÃO ESTADO CEARÁ (SEDUC). Plano Integrado de Educação Profissional e Tecnológica do Estado do Ceará. Ceará: mar/2008. Disponível em:

<http://webcache.googleusercontent.com/search?q=cache:VpyrBu6MpyYJ:testeplone.sct.ce.g ov.br/> Acesso em: 20 abril 2012.

SCHULTZ, T. W. O capital humano: Investimentos em educação e pesquisa. Tradução de Marco Aurélio de M. Matos. Rio de Janeiro: Zahar Editores. 1973. 250 p.

SILVA JUNIOR, João dos Reis. Reforma do Estado e da Educação no Brasil de FHC São Paulo: Xamã, 2002.

UNESCO. Declaração de Nova Delhi. Nova Delhi, 1993. Declaração mundial sobre educação para todos: Satisfação das necessidades básicas de aprendizagem. Jomtien, 1990 